\title{
Chapter 10 \\ Contemporary Portuguese Migration Experiences in Brazil: Old Routes, New Trends
}

\author{
Marta Vilar Rosales and Vânia Pereira Machado
}

\subsection{Introduction}

Emigration is deeply rooted in Portuguese history and culture. Over the centuries, people of different groups, religions and origins have moved to a multitude of places for diverse reasons, pursuing a wide range of goals. Contemporary transatlantic movements between Portugal and Brazil are, as they were in the past, characterised by bidirectional flows of people and things. These flows have constructed a migration path marked by colonialism, a shared language and, from the Estado Novo until the present, Freyre's Luso-Tropicalism. The first migrations took place in the fifteenth century and were driven in part by Portuguese colonial expansion policy (FeldmanBianco 2001). From then on, the Portuguese community has been the largest foreign community residing in Brazil. The recent global financial crisis had a strong impact on the Portuguese economy, resulting in high rates of unemployment and stagnant economic growth. Contrariwise, the Brazilian economy flourished during the same period (2008-2011), making the country attractive as a migration destination for diverse populations.

This chapter is one outcome of an extensive research project that investigated a specific trend in the recent wave of Portuguese emigration. This project's main research goal was to describe and analyse the on-going Atlantic Crossings between four major cities - Lisbon, Oporto, Rio de Janeiro and Sao Paulo - in order to reveal how the circulations of people and things between these cities mutually reinforce one another. Our research was based on a comparative ethnographic approach that included a vast array of methods (questionnaires, multi-sided participant and direct observation, interviews, statistical data analysis), and drew on the theoretical and methodological transnationalism approach of Glick-Schiller et al. (1994). It focused on the contemporary movements of people and things, their intersections and

M. V. Rosales (殴 · V. P. Machado

Instituto de Ciências Sociais, Universidade de Lisboa (ICS-UL), Lisbon, Portugal

e-mail: marta.rosales@ics.ulisboa.pt; vania.machado@ics.ulisboa.pt 
juxtapositions, and on the significance of old and new networks and relationships for the establishment of present-day migration routes. The four cities were selected on the basis of previous research results (Feldman-Bianco 2001; Malheiros 2011; Peixoto 2012), which identified them as major migration hubs on each side of the Atlantic. Our methodological design allowed us to gather substantive quantitative and qualitative data. We consider combining qualitative and quantitative data key to the analysis of the migration experiences, aspirations and values of the subjects involved, as well as for the framing of their experiences in the historical, political and economic context of Luso-Brazilian relations. Hence, this methodological approach allowed us to integrate different levels of analysis - descriptive and interpretative - while promoting a productive dialogue between structure and agency, universalism and particularism.

In this chapter, we will in particular explore the results of an extensive questionnaire that was distributed to all the households ${ }^{1}$ included in the research. This questionnaire's main objective was to produce descriptive sociographic profiles of the subjects and their families, as well to gather qualitative descriptive data on their migration trajectories and backgrounds, their networks of belonging, and their domestic material culture and consumption practices (Burrell 2008; Rosales 2010). Our analysis in this chapter will mainly focus on the data gathered from the households we interviewed in Rio de Janeiro and São Paulo, who had recently ${ }^{2}$ settled in these cities after arriving from Lisbon and Oporto. Even if the data we gathered cannot be considered representative of this particular migration trend, it produced significant information on original features of the contemporary Atlantic crossings - features such as the particular social composition of the households involved and their transnational positioning strategies. Our data also introduced new angles of analysis on the significant migration movements that have long existed between the two countries.

The chapter is structured around five topics: Portuguese migration to Brazil (a brief overview); Portuguese migration to São Paulo and Rio de Janeiro; profiles of the new migrant families; projects and expectations; and settling in a Brazilian city: materializing identity, belonging and positioning strategies.

\subsection{Portuguese Emigration: Waves and Numbers}

From 2008 to 2016, Portugal experienced a severe economic recession. This period of crisis had a strong impact on most of the country's institutions and affected all social spheres, including the migration movements in and out of the country. From an emigration perspective, the crisis significantly increased the number of people leaving the country (Peixoto and Iorio 2011) altering, for the first time in a

\footnotetext{
${ }^{1}$ A total of 100 interviews, 25 in each research site.

${ }^{2}$ The families arrived in Brazil between 2008 and 2015.
} 
considerable period, the balance of migration movements from positive, in $2010^{3}$, to negative, in 2011. Once a major structural dimension of Portuguese history - but absent from core academic and public debates for decades - emigration now regained its status as a significant research topic.

The consistent study of Portuguese migration is well documented and goes back to the beginning of the colonial project. In the fifteenth century, large contingents of mainland population left the continent and established themselves in Madeira and the Azores. Later on, Portuguese and European settlers migrated to the Portuguese African territories, to India and to Brazil.

By the second half of the eighteenth century, migration movements towards Brazil had become progressively more prominent, and before the turn of the century Brazil was already the main destination for those leaving Portugal in search of a better life. Migration to Brazil maintained quite a regular pattern, although its impacts were especially felt at times of internal political, social and economic turbulence. The most intense period of migration was the first decade of the twentieth century (1901-1911). The number of migrants decreased in the period between the two world wars, mainly due to the great depression (Pereira 2007) and the restrictive migration policy of the Vargas ${ }^{4}$ administration. The end of the long Portuguese dictatorship, in 1974, and accession to the EU, in 1986, had a significant impact on Portuguese emigration, both in terms of its intensity and social composition. On the one hand, a large contingent of people returned to the country as a result of decolonization. This incoming movement was paralleled by a significant decrease, as a whole, of the emigration flows that consistently drained the country's population during the 1960s. On the other hand, emigration to Brazil continued - both from Portugal and from the former African colonies - due to the radical political and economic changes imposed during the post-revolutionary period (Graça 2009). Unlike the emigration flows during the previous historical periods, which mainly consisted of people from the working classes, the second movement mostly involved people from the middle classes and the elites who had been in favour of the ancien regime. In the 1990s, Brazil received a new wave of Portuguese emigration, this time due to the Fernando Henrique Cardoso administration's policy of privatization ${ }^{5}$. During this period, known as "the return of the caravels" (Feldman-Bianco 2001), some of the largest Portuguese corporations regarded Brazil once more as a promising country to invest in, which led to a further migration wave.

More recently, the Brazilian economy experienced a boost as the country received intense media attention, not only because of its economic growth, but also because of two major global events: the Football World Cup (2014) and the Olympics (2016). This good economic period in Brazil coincided with a severe global economic crisis that had especially negative effects in Portugal. The Portuguese media quickly began to depict Brazil as an important alternative for the thousands of Portuguese

\footnotetext{
${ }^{3}$ Source: http://www.pordata.pt/Portugal/Saldos+populacionais+anuais+total++natural+e+migratorio-657 [03/09/14].

${ }^{4}$ Getúlio Vargas, Brazilian. Served as President twice: 1930-1945 and 1951-1954.

${ }^{5}$ Former Brazilian President, from 1995 to 2002.
} 
that opted - or were forced - to emigrate due to unemployment, financial problems and increasing social and politic instability. However, according to several official reports from Observatório da Emigração (Pires et al. 2014), Brazil received only 1\% of the Portuguese people who decided to migrate, with the great majority (80-85\%) of the overall contingent choosing European destinations.

Even if some of their statistical data on entries and exits seems to be incomplete and/or contradictory, the Brazilian Federal Police claim that the number of Portuguese who entered the country during 2001 was lower than 700 . The figures increased moderately in the next 7 years and in 2009 the situation clearly changed, with more than 3000 Portuguese entering the country. This trend reached a peak of 5700 people in 2013 and slowly decreased from then on to the present-day. This change reflects rising political and economic instability in Brazil, which has been affecting the country since 2014 .

\subsection{Portuguese Emigration to Rio and São Paulo}

The Portuguese are the largest community of residents in Brazil who were born outside the country (making up $23 \%$ of the total population born outside Brazil in 2010). Most of the 137,973 individuals within this category reside in São Paulo (47\%) and in Rio de Janeiro (37\%) and arrived in these cities before 1970, which makes them a considerably old group ${ }^{6}$. The number of entries of Portuguese citizens decreased during the following decades, until 2011, when the number of arrivals increased more than $100 \%$ compared with the previous period and continued to grow until 2013. Forty-four percent of all residence permits issued to Portuguese nationals during that year were for the São Paulo area and $20 \%$ for the Rio de Janeiro area. This data only covers official requests for residence permits and does not include other migration situations, such as family reunions and people who entered the country with tourist or student visas. This new group of Portuguese migrants coexists with the previous one - the group that arrived in the 50s and $60 \mathrm{~s}-$ which allows the two contingents to be compared. This comparison enables a more comprehensive view of Portuguese migration to Brazil and its impact on the relationship between the two countries.

\subsection{Who Are They?}

The people interviewed during this research do not constitute a representative sample of all recent Portuguese migrants. However, even though representativeness was not a significant concern from the beginning, the different social, economic and legal statuses of the subjects approached during fieldwork was visible from the start

${ }^{6}$ IBGE, Censos 2010. 


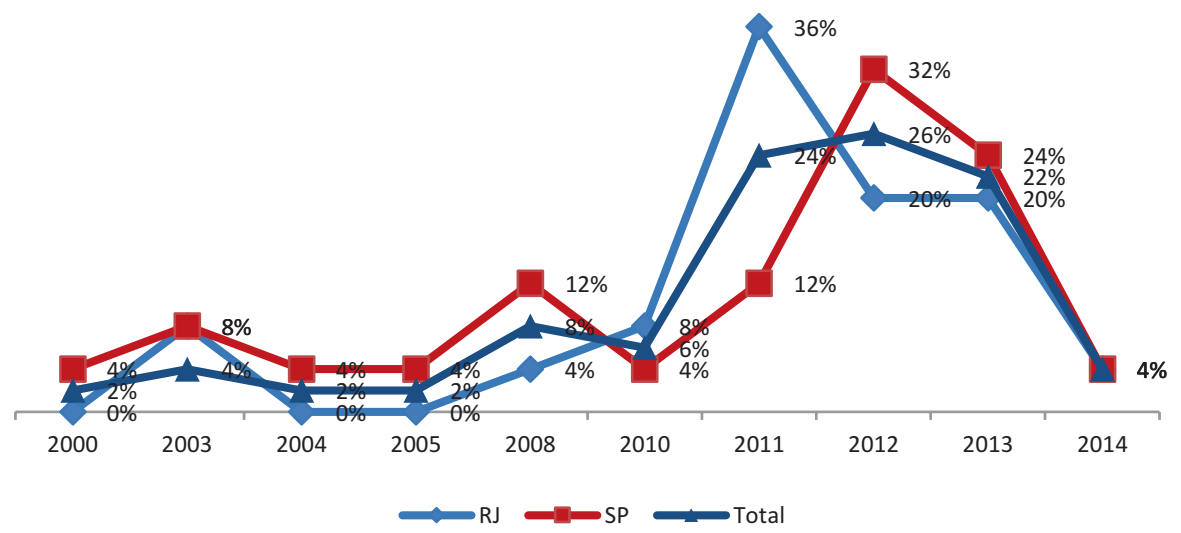

Fig. 10.1 Year of arrival of Portuguese migrants in Brazil by destination (\%).

Source: Survey on materiality, contemporary movements and policies of belonging. ATLANTIC CROSSINGS Project

and, therefore, taken into account during the selection stage. The sample includes a diverse range of subjects in terms of gender, formal education, professional backgrounds, migration backgrounds and origin (Oporto and Lisbon). Recognising this diversity within the small group of 50 Portuguese migrants and their families involved in our research helped illuminate the particularities of their social profiles, as well as of their future projects, desires and hopes ${ }^{7}$.

Both the quantitative and qualitative stages of the research revealed a significant difference in the number of migrants originating from Lisbon and from Oporto (only 16\% of all subjects in Rio de Janeiro and 12\% in São Paulo are from Oporto). The fact that migration movements are often structured transnational networks which help to prevent the dangers associated with emigration (Glick-Schiller et al. 1994; Vertovec 2007) - might explain this difference. These numbers may reveal the existence of a more solid migration network out of Lisbon than out of Oporto.

Figure 10.1 presents emigrants' year of arrival in the two Brazilian cities. The data is in keeping with the overall picture painted by official Brazilian statistics on the entries of foreign citizens. The number of entries increases significantly from 2008 to 2012 (with spikes in 2011 (Rio 36\%) and 2012 (São Paulo 32\%)).

The ratio of men and women included in the research sample $-46 \%$ and $54 \%$ respectively - partially contradicts the figures of the Brazilian authorities, which show a much higher presence of male than of female migrants $(65 \%$ and $35 \%$, respectively). The age profile is also moderately different in the two cities. The average age in Rio is 34, where $65 \%$ of the subjects are between 25 and 34 years old. The subjects residing in São Paulo are older than those in Rio, with an average age of 40 (52\% of them older than 40). The difference between the two groups' professional profiles helps clarify the reason for the age gap between them. The typical profile of

\footnotetext{
${ }^{7}$ The research only included individuals and their families who migrated from Lisbon and Oporto to Rio de Janeiro and São Paulo after 2000.
} 
a Portuguese citizen residing in Rio is that of a young person who has recently graduated in the arts, architecture or engineering. In São Paulo, the typical profile is that of a mid-career professional working in the business or finance sectors. Most subjects in these groups are married. This trend is particularly significant in São Paulo, where only $16 \%$ of emigrants are single. And even if the number of single people in Rio is higher (44\%) - mainly due to the respondents' youth and lack of professional stability - the majority of these migration projects are planned as collective, and often family-oriented, projects. The two groups are also similar in their formal education qualifications. Most subjects have got degrees, and half of them have completed post-graduate programmes (48\% in Rio and 56\% in São Paulo). This contrasts with the level of formal education of the former migrant contingents, which were mainly made up of low-income and low-skilled individuals. The majority of higher education qualifications were obtained in Portugal. However, the percentage of degrees completed outside Portugal is considerable (24\%). All the qualifications were obtained before migration. This fact illustrates the importance of internationalization and mobility in structuring the respondents' professional and personal trajectories - as well as the significance of cosmopolitanism as a general added value which "has been further heightened by the elaboration of a public discourse within many industrialised countries that trumpets the importance of "international experience' within a globalizing economy" (Amit 2011 [2007]: 6).

The qualitative data we gathered during fieldwork revealed that there were few job opportunities at the time for unskilled Portuguese workers in Brazil. Even if Rio and São Paulo were undertaking major urban transformations and experiencing an investment boost in all sectors, the existence of large contingents of low-cost Brazilian workers living in the cities' peripheries resolved the extraordinary need for manpower. Hence the subjects' high social and cultural capitals (cf. Bourdieu 1979) reflect the specificities of the job market, which mostly needed highly-skilled workers at that time.

As mentioned before, the groups involved in our research coexist in the cities with other Portuguese migrants who arrived in the 50s and 60s. These older groups are well organised as migrant communities. In both cities, there is a plurality of migrant associations and social clubs offering a wide range of cultural activities, as well as very active economic associations created to defend community business interests. All these associations and clubs are well integrated in their city's social, economic and political spheres and are fully recognised by Brazilians.

The social profiles of the subjects and their families were explored mainly through an analytical lens that privileged qualitative data. Habitus (Bourdieu 1984 [1979]) and all the conceptual tools related to this central concept, such as taste and lifestyle, were key to investigating the subjects' expectations and trajectories as recent migrants in Rio and São Paulo. The great majority of the subjects have got Portuguese nationality (96\% in São Paulo and $76 \%$ in Rio) and do not plan to apply for Brazilian citizenship (74\%). The subjects justify their lack of interest in becoming Brazilian by arguing that holding a European passport has got an added value that holding a Brazilian one does not have and, also, that they feel a great lack of identification with, in their words, the Brazilian identity. Both thoughts show a clear 
valorisation of Europe that is complementary to a paternalistic attitude towards Brazil, which is still influenced by the colonial past and post-colonial present-day relations between the two countries. On the one hand, Brazil is considered a friendly and familiar context in which to live, i.e. a place where the local population understand and positively value the Portuguese people and culture. On the other hand, according to the subjects, while the Portuguese feel at home in Brazil - i.e. they are familiar with the culture and the population's ways of life - they do not necessarily identify with Brazilian people.

The families' income is mainly from work (72\% in Sao Paulo and 84\% in Rio). In São Paulo, the centrality of work is especially evident for males, since the subjects claiming to be living off other family members' income (16\%) and off scholarships (12\%) are predominantly female. These figures draw attention to the fact that the number of Portuguese women that do not work in the city is comparatively high. These women migrated to Brazil due to their husbands' professional projects and do not carry out any remunerated activity. The majority of those who engage in remunerated professional activity have full-time positions (76\% in São Paulo, 84\% in Rio). Of these, $20 \%$ are self-employed professionals, who are mainly based in Rio. It is also worth noting that the percentage of business owners in São Paulo is considerable (24\%) and, finally, that underemployment and unemployment are not widespread and mainly affect women residing in São Paulo.

As expected, the migrants' professional profile is strongly related to their capital. In Rio, 95\% of the subjects belong to the category "Specialists in the Academic and Scientific sector". In São Paulo, half of the subjects work in this sector (48\%), while the other half fall into the category of "Senior Partners in the Business sector" (33\%). Even if this data paints a positive picture of the migrants' professional status in Brazil, it is important to stress that some of them are working without a formal contract, which is described as normal practice in general, and in Rio in particular. A considerable proportion of the subjects who stated they were full-time employees are, in fact, in a vulnerable position since they are paid below-average salaries and are not entitled to any kind of health, social or unemployment benefit. The lack of a formal contract affects many aspects of life. It makes it impossible to formally rent a house or open a bank account. This situation contradicts the migrants' initial expectations about life in Brazil and introduces a note of permanent insecurity and instability in their daily lives.

The difficulty of getting academic qualifications and degrees formally recognised constitutes a second major problem, especially for those who want a job in the public sector. The bureaucratic complexity of the process is a major factor behind most situations of underemployment, and is especially problematic amongst lawyers, architects and engineers, who see their attempts to join the professional orders blocked by lack of recognition of their diplomas.

We compared data on the subjects' last professional position in Portugal and their present position in order to identify and explore possible mobility trajectories. In Rio, most subjects kept the same profession (80\%) they had in Portugal, while in São Paulo this tendency, even if dominant, is less evident (65\%). Being able to work and hold good professional positions in one's professional field is considered a very 
important goal for the group. In fact, it is the main reason for their migrating to Brazil since, according to them, Portugal was not offering them the opportunity to accomplish it. Arguments about the quality and specificity of their professional skills are also used to draw a line between themselves and the other Portuguese migrants from previous waves who were, in their words, uneducated people mainly bakers and small retail businessmen.

A significant number of subjects - even very qualified migrants - said they found their jobs through informal contacts (35\%), a statement that attests to the significance of social networks. Only $15 \%$ of jobs (mainly those in the public sector) came from a formal job application.

\subsection{Life Projects}

The decision to migrate plays a very significant part in the group's short- and longterm plans. Our research explored these migrants' expectations in order to identity the main features of their trajectories.

The subjects' discourses confirm the existence of a plurality of reasons motivating their decision to migrate. There is a clear cleavage between the discourses gathered in the two cities. The São Paulo group says that the economic opportunities (in terms of jobs and business) that the city was offering at the time were a great incentive to migrate, while the migration of the group based in Rio was mainly due to their need to experience something new and different from their life in Portugal. Interestingly, both groups explicitly avoid connecting their decision to migrate to the economic crisis Portugal was facing. There is no direct mention of economic factors such as unemployment, job insecurity or lack of career prospects. On the contrary, all the emigrants' arguments are constructed around the advantages Brazil had to offer at the time in economic and social terms, and underline that their quality of life significantly improved with migration, in spite of their basically solid professional integration and income level in Portugal. This original trend echoes the arguments put forward by some contemporary authors, who draw attention to the fact that lifestyle motivations are gaining weight in contemporary migration (Benson and O'Reilly 2009). The group members we studied share a quest for better life conditions, i.e. better quality of life, with the great majority of the world's migrant population. Quality of life is, according to our research subjects, mostly the result of two factors: the new place of residence - i.e. the Brazilian cities they now inhabit and the fact that migration allowed them to restart their lives - i.e. that migration provided both the setting and the tools for a transformative process to occur, a process that allowed them to be more in tune with their true self and true identity and to materialise a new way of living (Amit 2011; Benson and O'Reilly 2009).

Migration is defined, in most cases, as a natural option, resulting mainly from an individual or a couple's decision. Once more, the group distances itself from the other Portuguese emigrants who arrived before them who, in their opinion, did not have a choice. Unlike most of their fellow countrymen and women - for whom 
migration was a last resort, a sacrifice made in order to escape poverty - the group defines itself as mobile by preference. This self-definition establishes a direct connection between migration and cultural capital and justifies their decision to migrate as a decision to upgrade their own knowledge of the world.

Emphasising personal experience and cosmopolitanism does not, however, indicate that the group devalues work and economic capital. In fact, and in spite of their praise for a cosmopolitan lifestyle and for the quality of life in Brazil, the data gathered suggests that this group's careers are an important dimension of their daily lives. In fact, the data gathered on this topic illustrates that the existence of job opportunities strongly influenced their choice of destination city, especially amongst the migrants who opted to live in Rio. The figures in Table 10.1 show that this was considered the most significant pull factor both in Rio (52\%) and in São Paulo (48\%), which corroborates the claim that economic factors play a significant role in contemporary Portuguese skilled emigration.

The importance of a common historical past, the existence of strong colonial and post-colonial ties between Portugal and Brazil, and the fact that the countries share the same language is considered the second main pull factor in Rio (48\%) but is less significant for the São Paulo group (24\%). The latter considers the positive international representation of Brazil more significant (40\%), since it directly influences their professional careers and the business climate. Previous knowledge of the city (24\%), the existence of social networks of support (32\%), and a positive representation of Brazil (36\%) are particularly significant for the group residing in Rio. However, for the Rio group - unlike the São Paulo group - this last factor is not valued because it translates into economic and professional gains, but rather because it shows that Brazil is valorised as a vibrant cultural context with beautiful landscapes, populated by easy-going and happy people. Family regrouping is also considered a strong motivation for migration amongst the group (28\% in Rio de Janeiro and 32\% in Sao Paulo). Although this reason is given almost exclusively by women, it is possible to identify different situations in each city. In São Paulo, women (as well as children) tend to follow their husbands, who migrated mostly due to their professional careers. In Rio, there are two distinct trends: a trend of

Table 10.1 Migration pull factors by destination

\begin{tabular}{l|l|l|l}
\hline & RJ $(\%)$ & SP $(\%)$ & Total $(\%)$ \\
\hline Job opportunities & 52 & 48 & 50 \\
\hline Positive representations of the country & 36 & 40 & 38 \\
\hline Cultural and linguistic affinity & 48 & 24 & 36 \\
\hline Family reunification & 28 & 32 & 30 \\
\hline Friendship network & 32 & 12 & 22 \\
\hline Attractive climate & 28 & 16 & 22 \\
\hline Previous knowledge of the city & 24 & 16 & 20 \\
\hline Family network & 4 & 12 & 8 \\
\hline Source: Survey & & 12 & \\
\hline
\end{tabular}

Source: Survey on materiality, contemporary movements and policies of belonging. ATLANTIC CROSSINGS Project 
mixed couples (where one spouse is Brazilian) migrating; and a trend of one partner deciding to follow the other partner who has already migrated.

Moving to a significantly different context is always stressful, and is mediated by numerous concerns, fears and expectations. Experiencing difficulties in adapting to and integrating into a new social context is more significant among the São Paulo group (40\%), than among those settling in Rio de Janeiro (20\%). The fear of not finding a proper job is not significant for the São Paulo group (8\%), since almost all subjects had already found a suitable job before leaving Portugal. In contrast, the Rio group expressed considerable concern at not being able to find and hold secure and stable jobs (20\%). It is worth mentioning that, once more, the shared history of the two countries played a significant part in attenuating anxieties about the new urban contexts they were entering.

The data gathered on preparation for migration (Table 10.2) suggests the existence of different migrant profiles among the group.

São Paulo seems to be the preferred city for those openly seeking job opportunities for highly qualified people. This group stated that they had also looked for positions that would boost their careers in other destinations such as the USA, other stronger European economies, and some of the former Portuguese African colonies (e.g. Angola and Mozambique). Their migration projects are highly structured and carefully planned, and represent an important milestone in the subjects' professional and personal biographies. The Rio group, however, presents a profile that contrasts with this. Rio de Janeiro is represented as an attractive context for very young qualified people, who are in the early stages of their professional careers. Subjects evaluate the city positively with respect to job opportunities, especially when compared to Lisbon and Oporto at the time they migrated. But the most significant theme in their discourse about the city is how great Rio is as a place to live, its

Table 10.2 Other destinations considered by respondents

\begin{tabular}{l|l|l|l}
\hline São Paulo & N & Rio de Janeiro & N \\
\hline USA & 5 & Argentina & 3 \\
\hline Germany & 2 & Australia & 2 \\
\hline UK & 2 & Brazil & 2 \\
\hline Uruguay & 1 & Mexico & 2 \\
\hline Denmark & 1 & Norway & 2 \\
\hline Cape Verde & 1 & New Zealand & 1 \\
\hline Mozambique & 1 & Angola & 1 \\
\hline Angola & 1 & Colombia & 1 \\
\hline Canada & 1 & USA & 1 \\
\hline Switzerland & 1 & India & 1 \\
\hline & & UK & 1 \\
\hline & & Macao & 1 \\
\hline
\end{tabular}

Source: Survey on materiality, contemporary movements and policies of belonging. ATLANTIC CROSSINGS Project 
wonderful weather and its relaxed way of life. The allure of life in Rio is the main reason why most of the respondents migrated without pre-arranging a job, housing and, in some cases, even a visa permit. Many of them define themselves as cosmopolitans, true citizens of the world who embrace a lifestyle that revolves around permanent mobility and transition (Fig. 10.2).

The subjects based in Rio are highly mobile. Not only have a high proportion migrated previously $(68 \%)$; in most cases they had previously migrated more than twice in addition to their current migration. They consider these previous experiences key to their current migration. Many of the subjects had visited Rio previously, and nearly half of them had migrated in the past to other destinations such as the USA, the Portuguese-speaking African Countries, the Middle East, and Australia (Fig. 10.3).

In São Paulo, only $32 \%$ of the respondents had a previous migration experience. Their destinations were also more restricted than those of the Rio group. The subjects for whom this is their first migration experience are all married (or divorced)

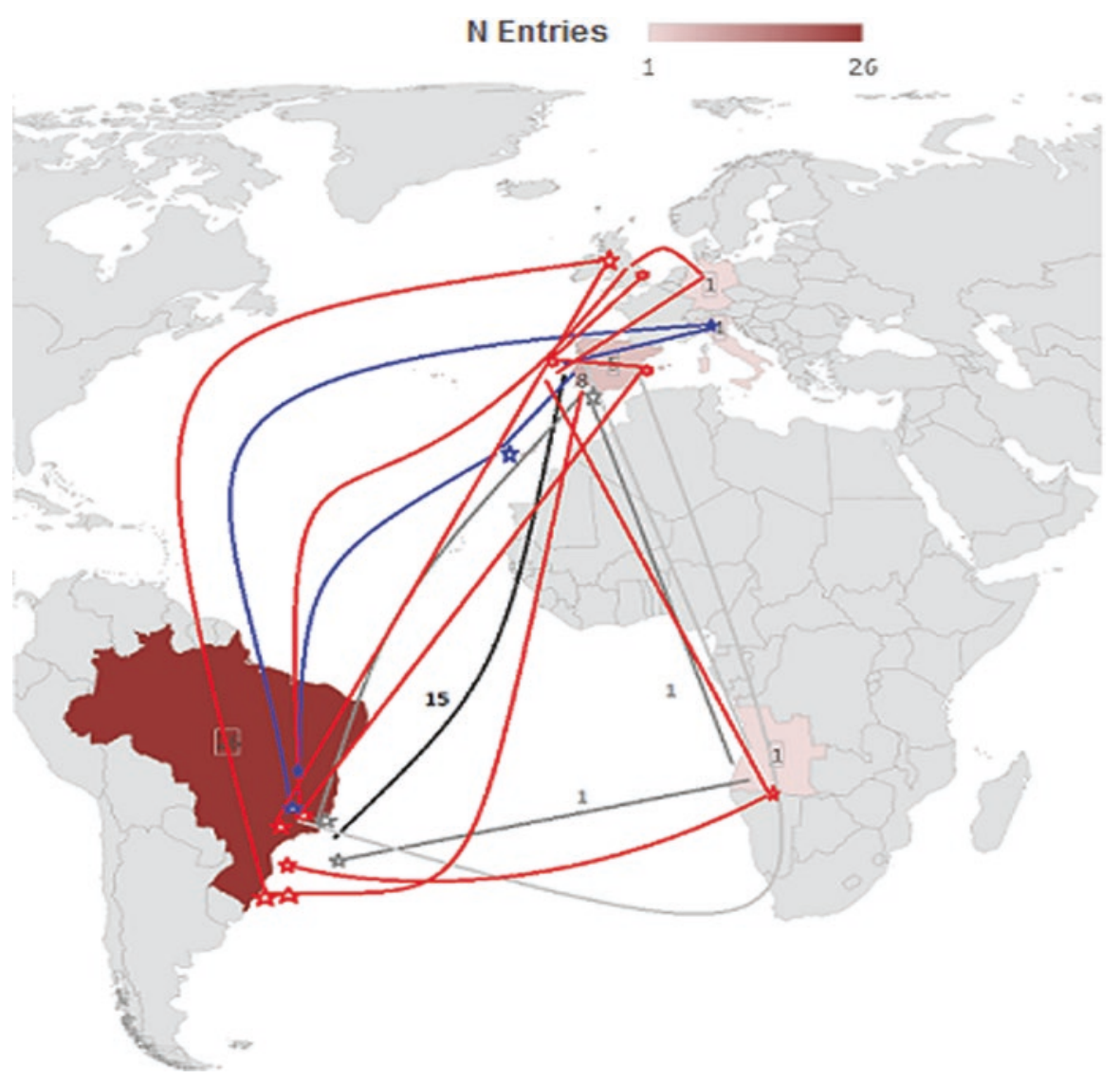

Fig. 10.2 Migratory routes of Portuguese people living in Rio de Janeiro 


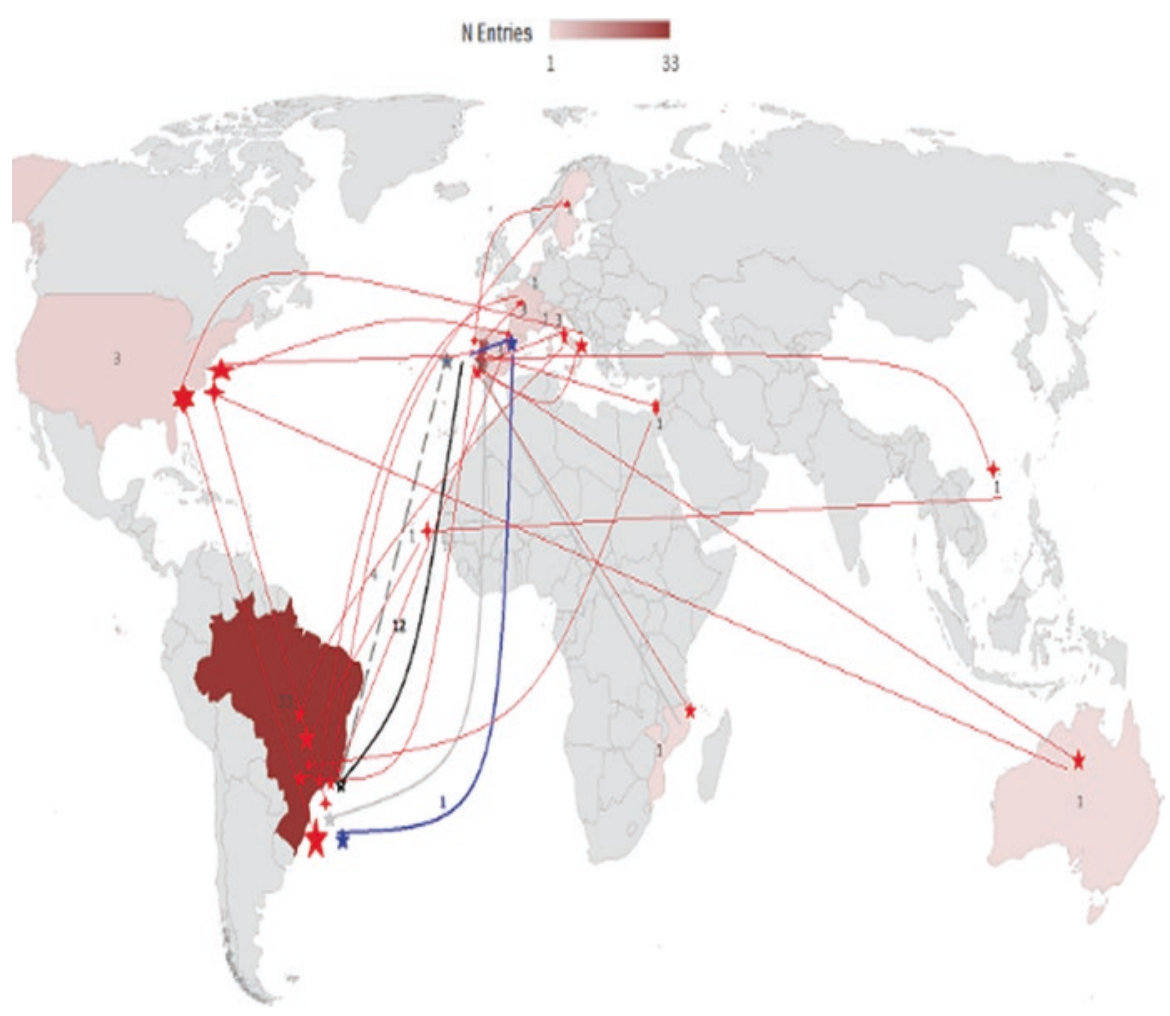

Fig. 10.3 Migratory routes of Portuguese people living in São Paulo

and their spouses and children migrated with them. Their previous migration destinations were most often Spain, the Netherlands, Angola and the US. These experiences were interrupted by a period of time in Portugal, before the subjects departed again for Brazil.

Future migration plans were, at the time, still unclear for most of the subjects in the two cities. A considerable part of the São Paulo group (20\%) aims to return to Lisbon after a short time. The idea of returning home coexists with the idea of migrating to the USA, the UK or Australia (18\%) in the near future. The group from Rio is not very interested in returning to Portugal (only $8 \%$ said that was a possibility) and $24 \%$ of the subjects are considering future migration to new destinations such as Canada, the UK and the USA, but not in the near future.

\subsection{Lifestyles and Leisure Activities}

How different is life in Brazil, when compared with the subjects' past life in Portugal? And how do they evaluate their current routines and ways of living? 
The groups' quest for a better existence was explored through a series of topics related to life quality. The research used a Likert scale (1 - I am doing much worse now; 6 - I am doing much better now) to grade the subjects' responses. The respondents were also asked to signal if their current situation matched their expectations preceding migration. Table 10.3 presents the mean and median values for the different topics. It is important to note that, in spite of the negative values for several structural factors (e.g. housing, security, health services, education and cost of living), the gain in personal achievements following migration was positive at the time ( 4.4 mean value).

The reason behind the negative evaluation of the health and educational systems is the cost of these services in the private sector. The low quality of Brazilian public services has pushed most of the families we studied towards the private sector. This fact is considered a major downgrade when compared with the situation they experienced in Portugal. According to our research subjects, the quality of these basic services is good, but they cost much more than in Portugal. The families who cannot afford private healthcare and schooling mentioned the low quality and the near nonexistence of public services in both cities. The housing market is, in most cases, also negatively evaluated. The high prices and the small dimensions of most houses, especially in the city centre, were frequently mentioned. More than half of the families said that they were surprised at the high rents and that they had to make adjustments to their expectations.

A considerable number of respondents devalue the lack of a solid welfare system and the instability of the job market in Rio. As was mentioned before, the possibility of experiencing new situations, meeting new people and being mobile compensates for the economic instability experienced by some of the subjects based in Rio. In São Paulo, this adventurousness is only embraced by some of the younger families. The more senior research subjects $(40 \%)$ mention the lack of time to be with their families, since both the working hours and the traffic in the city are much heavier

Table 10.3 Previous and current situation by destination

\begin{tabular}{l|l|l|l|l|l}
\hline & \multicolumn{2}{l}{} & \multicolumn{2}{l}{ SJ } & Total \\
\cline { 2 - 6 } & Mean & Me & Mean & Me & Mean \\
\hline Personal achievements & 4.4 & 4 & 4.3 & 5 & 4.4 \\
\hline Free time and leisure & 4.6 & 5 & 4 & 4 & 4.3 \\
\hline Career opportunities & 4.4 & 5 & 3.7 & 4 & 4.1 \\
\hline Integration and belonging & 3.8 & 4 & 4.3 & 4 & 4.1 \\
\hline Travel and sports' activities & 3.9 & 4 & 3.9 & 4 & 3.9 \\
\hline Income & 4.1 & 4 & 3.6 & 4 & 3.9 \\
\hline Freedom & 3.7 & 4 & 3.5 & 3 & 3.6 \\
\hline Expenses & 2.9 & 3 & 3.5 & 3 & 3.2 \\
\hline Housing & 2.8 & 3 & 3.5 & 3 & 3.2 \\
\hline Education & 2.7 & 2 & 3.4 & 4 & 3.1 \\
\hline Health care & 2.3 & 2 & 3.2 & 3 & 2.8 \\
\hline Safety & 1.8 & 2 & 2.3 & 2 & 2.1 \\
\hline Total & 3.4 & & 3.7 & & 3.6 \\
\hline
\end{tabular}

Source: Survey on materiality, contemporary movements and policies of belonging. ATLANTIC CROSSINGS Project 
than in Portugal. In contrast, most families in Rio state that they have more free time now than they have ever had. This free time will, in their words, hopefully allow them to materialise their romantic dreams of a life on the beach, playing sport daily and travelling - i.e. a very different picture from the image of hard work and money saving commonly associated with Portuguese migration. Whether this idyllic picture will ever be realised is a major topic to be explored in another article.

\subsection{Final Remarks}

The contemporary movement of Portuguese people to Rio de Janeiro and to São Paulo is the most recent episode of a longstanding trend - a trend that has been central in the history of Atlantic Crossings from Southern Europe to South America. This is an old migration route, travelled many times in contexts of economic and/or political instability by the Portuguese, who have crossed the Atlantic to pursue better lives for themselves and for their families. The fact that the two countries share a colonial past has always played a significant part not only in their political, cultural and diplomatic relations, but also in the positions that each nation's citizens occupy, as migrants, in the other country. As was argued before, present-day Portuguese migrants in Brazil do not identify themselves as migrants. Instead, they define themselves as cosmopolitans or travellers in search of new life experiences and/or professional internationalization in two great Brazilian cities. Colonialism and post-colonialism appear to facilitate this particular positioning strategy. By promoting cultural attachment and naturalizing the movements of Portuguese people towards Brazil and, simultaneously, diminishing Brazilian culture, institutions and health and educational systems, this new Portuguese migration wave seems to be contributing to the reification of a hierarchical relationship between the two countries, as well as to the exoticization of the "easy" Brazilian way of life.

Funding Research funded by the Fundação para a Ciência e a Tecnologia (Foundation for Science and Technology, FCT) (PTDC/CS-ANT/119803/2010) for the project "Atlantic Crossings: materiality, contemporary movements and politics of belonging" (Travessias do Atlântico: materialidade, movimentos contemporâneos e políticas de pertença). The proofreading of this chapter was funded by the Portuguese Emigration Observatory (Observatório da Emigração).

\section{References}

Amit, V. (Ed.). (2007). Going first class?: New approaches to privileged travel and movement (Vol. 7). London: Berghahn Books.

Benson, M., \& O'Reilly, K. (2009). Migration and the search for a better way of life: A critical exploration of lifestyle migration. The Sociological Review, 57(4), 608-625.

Bourdieu, P. (1984 [1979]). Distinction: A social critique of the judgement of taste. Cambridge: Harvard University Press. 
Burrell, K. (2008). Managing, learning and sending: The material lives and journeys of Polish women in Britain. Journal of Material Culture, 13(1), 63-82.

Feldman-Bianco, B. (2001, December). Brazilians in Portugal and Portuguese in Brazil: Constructions of sameness and difference. Global Studies in Culture and Power, 4(8), 607-650.

Glick-Schiller, N., Basch, L., \& Blanc-Szanton, C. (1994). Nations unbound: Transnational projects, postcolonial predicaments and deterritorialized Nation-States. Amsterdam: Gordon and Breach Science Publishers.

Graça, M. Q. (2009). Portugueses no Brasil no pós-25 de Abril, um testemunho contra os estereótipos. In B. Padilla \& M. Xavier (Eds.), Revista Migrações - Número Temático Migrações entre Portugal e América Latina (Vol. 5, pp. 288-290). Lisboa: ACIDI.

Malheiros, J. M. (Ed.). (2011). A Imigração brasileira em Portugal. Lisbon: ACIDI.

Peixoto, J. (2012). A emigração portuguesa hoje: o que sabemos e o que não sabemos (SOCIUS Working Papers, 5).

Peixoto, J., \& Iorio, J. (2011). Crise, imigração e mercado de trabalho em Portugal. Cascais: Principia.

Pereira, M. H. (2007). A Emigração portuguesa para o Brasil e a geo-estratégica do desenvolvimento Euro-Americano. In AAVV (Ed.), População e sociedade: A emigração portuguesa para o Brasil, Parte I, 14.

Pires, R. P., Pereira, C., Azevedo, J., \& Ribeiro, A. C. (2014). Emigração Portuguesa: Relatório Estatístico 2014. Observatório da Emigração e Rede Migra, CIES-IUL, ISCTE-IUL.

Rosales, M. V. (2010). The domestic work of consumption. Materiality, migration and homemaking. Etnográfica, 14(3), 507-525.

Vertovec, S. (2007). Introduction. New directions in the anthropology of migration and multiculturalism. Ethnic and Racial Studies, 30(6), 961-978.

Open Access This chapter is licensed under the terms of the Creative Commons Attribution 4.0 International License (http://creativecommons.org/licenses/by/4.0/), which permits use, sharing, adaptation, distribution and reproduction in any medium or format, as long as you give appropriate credit to the original author(s) and the source, provide a link to the Creative Commons licence and indicate if changes were made.

The images or other third party material in this chapter are included in the chapter's Creative Commons licence, unless indicated otherwise in a credit line to the material. If material is not included in the chapter's Creative Commons licence and your intended use is not permitted by statutory regulation or exceeds the permitted use, you will need to obtain permission directly from the copyright holder. 